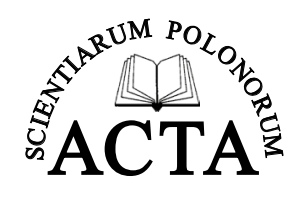

www.food.actapol.net

Acta Sci. Pol. Technol. Aliment. 16(2) 2017, 171-179

pISSN 1644-0730

eISSN 1898-9594

http://dx.doi.org/10.17306/J.AFS.2017.0478

ORIGINAL PAPER

Received: 5.03 .2017

Accepted: 5.06.2017

\title{
LACTOSE-FREE FROZEN YOGURT: PRODUCTION AND CHARACTERISTICS
}

\author{
Katarzyna Skryplonek ${ }^{1 凶}$, David Gomes², Jorge Viegas², Carlos Pereira², \\ Marta Henriques² \\ ${ }^{1}$ Department of Dairy Technology and Food Storage, West Pomeranian University of Technology \\ Papieża Pawła VI 3, 71-459 Szczecin, Poland \\ 2Department of Food Science and Technology, College of Agriculture, Polytechnic Institute of Coimbra \\ Bencanta 3045-601 Coimbra, Portugal
}

\begin{abstract}
Background. Nowadays, consumer demand is driving better and more nutritious dairy products. Changing from traditional to new lactose-free products poses technological challenges for the food industry in order to maintain or improve their food characteristics and consumer preferences.

Material and methods. This study investigates the production of lactose-free frozen yogurt by enzymatically hydrolysis of lactose, and its influence on the final product characteristics. In the case of lactose-free products, commercial Ha-lactase ${ }^{\circledR}$ was used for hydrolysis, and the reaction occurred simultaneously with fermentation. The effect of lactose hydrolysis on the physicochemical properties, texture, viscosity, overrun and sensory attributes in the final product was investigated.

Results. After yogurt maturation, the acidity of the lactose-free product was significantly higher than in the control, suggesting that breaking down lactose enhances the fermentation process. Lactose-free frozen yogurt had significantly lower hardness and stickiness and higher viscosity than control frozen yogurt. Moreover, lactose hydrolysis promoted a smooth and creamy consistency, whereas in the case of conventional products a coarse structure, due to the presence of large ice crystals, was identified. Hydrolysis of lactose also improved the sweetness and brightness of frozen yogurt. The improved textural properties of lactose-free product results from the fact that monosaccharides produced during lactose hydrolysis depress the freezing point of the mix, which enables product with softer structure and bigger resistance to ice recrystallization to be obtained.

Conclusion. The study showed that lactose-free frozen yogurt may be used successfully for production of novel lactose-free frozen desserts. Lactose hydrolysis improves the texture and viscosity of the product, as well as enhancing its sensory quality.
\end{abstract}

Keywords: frozen yogurt, lactose-free, lactose hydrolysis, lactase, texture, viscosity

\section{INTRODUCTION}

Frozen yogurt, also known as a yogurt ice cream, is a dairy frozen dessert which combines the sour, refreshing taste of yogurt with the attributes of ice cream. Nowadays, it can be observed that consumers are more aware of the connection between their diet and health. Frozen yogurt is perceived as a healthier alternative to ice cream (Isik et al., 2011; Milani and Koocheki, 2011). Frozen yogurt contains a considerably

凶katarzyna.skryplonek@zut.edu.pl 
lower amount of fat (3.25-6\%) in comparison with ice cream (10-16\%) (Marshall, 2003) and it is well known that excessive intake of fat is connected with a higher risk of obesity and cardiovascular diseases (Devereux et al., 2003). Moreover, frozen yogurt is a source of lactic acid bacteria, which are able to survive in the product even during one-year storage (Lopez et al., 1998).

Lactose is a disaccharide present in milk and dairy products consisting of glucose and galactose (Gänzle et al., 2008). It is estimated that $75 \%$ of the world's adult population has a low level of activity of lactase, the enzyme responsible for lactose hydrolysis. This results in lactose digestion problems and lactose intolerance symptoms, like stomach discomfort after consuming dairy products. The prevalence of this syndrome is ethnicity-dependant, for instance it affects $100 \%$ of Asians and only $2 \%$ of Northern Europeans (Brown-Esters et al., 2012; Messia et al., 2007). Apart from lactose maldigestion, this disaccharide has some technological disadvantages. The sweetness of lactose solutions is about 5 times lower than of sucrose. To enhance the sweet taste, dairy products require a substantial amount of sugar to be added, which in the case of ice cream ranges from 10 to $14 \%$ (Goff and Hartel, 2004). In comparison with other disaccharides, lactose has a low solubility that at ambient temperature is about 10 times lower than that of sucrose. Owing to this, lactose is susceptible to crystallization. The growth of crystals is reported as a specific defect of concentrated products such as condensed milk. This problem also occurs in ice cream, because during freezing the amount of free water decreases and the concentration of lactose increases rapidly in the aqueous phase. Too big lactose crystals may be detectable in mouth and causing a rough or gritty sensation known as sandiness (Gänzle et al., 2008).

One possible method to tackle this is lactose hydrolysis with the usage of the enzyme $\beta$-galactosidase (lactase). Breaking down lactose into galactose and glucose results in an increase in the solubility, higher sweetness and expanded availability of the product for consumers with lactose intolerance (Gänzle et al., 2008). Moreover, the monosaccharides that result from a reduction the freezing point of the ice cream mix, improve the texture of the product, which is softer and easier to scoop (Goff and Hartel, 2004).
In this context, the work aim to produce a lactosefree frozen yogurt with acceptable nutritional, sensory and rheological qualities. Lactose was enzymatically hydrolysed to glucose and galactose simultaneously with yogurt fermentation. The effect of lactose hydrolysis on the physicochemical properties, texture, viscosity, overrun and sensory attributes in the final product was investigated.

\section{MATERIALS AND METHODS}

\section{Materials}

Whole milk, cream and skimmed milk powder were purchased from a local supplier and delivered to the pilot dairy plant at College of Agriculture of Polytechnic Institute of Coimbra. Sucrose in the form of commercial sugar was purchased at a local marked. An enzyme Ha-lactase ${ }^{\circledR}$ and a freeze-dried yogurt starter culture (YF-L903) with a traditional composition (Lactobacillus delbrueckii ssp. bulgaricus and Streptococcus thermophilus) were produced by $\mathrm{Chr}$. Hansen (Denmark). All the chemical reagents used were analytical grade.

Frozen yogurt production. Lactose-free and control frozen yogurts were prepared according to the scheme presented in Figure 1.

Whole milk (3.5\% fat, $10.2 \%$ MSNF - Milk Solids Not Fat), cream (35\% fat, $6.8 \%$ MSNF) and skimmed milk powder ( $1 \%$ fat, $97 \%$ MSNF) were mixed with a home-type blender in the right proportions to obtain a mixture with $5 \%$ fat and $12 \%$ MSNF. Next, the sucrose was added $(6.5 \mathrm{~g} / 100 \mathrm{~g})$ and the mixture was heated and blended to dissolve all the ingredients. Although, according to Marshall (2003), the typical sugar content in frozen yogurt ranges between 10 and $14 \mathrm{~g} / 100 \mathrm{~g}$, in the present study a lower concentration was used because the resulting products of lactose hydrolysis, galactose and glucose contributed sweetness and should enhance the sweet taste of the final product. The mixture was then subjected to batch pasteurization at $95^{\circ} \mathrm{C}$ for $5 \mathrm{~min}$ (recommended by the enzyme manufacturer) and cooled down to $44^{\circ} \mathrm{C}$. After cooling, the mixture was divided into 2 batches. One with lactase incorporated and the other working as the control without the enzyme. The procedure of lactose hydrolysis in the yogurt was performed in accordance with the 


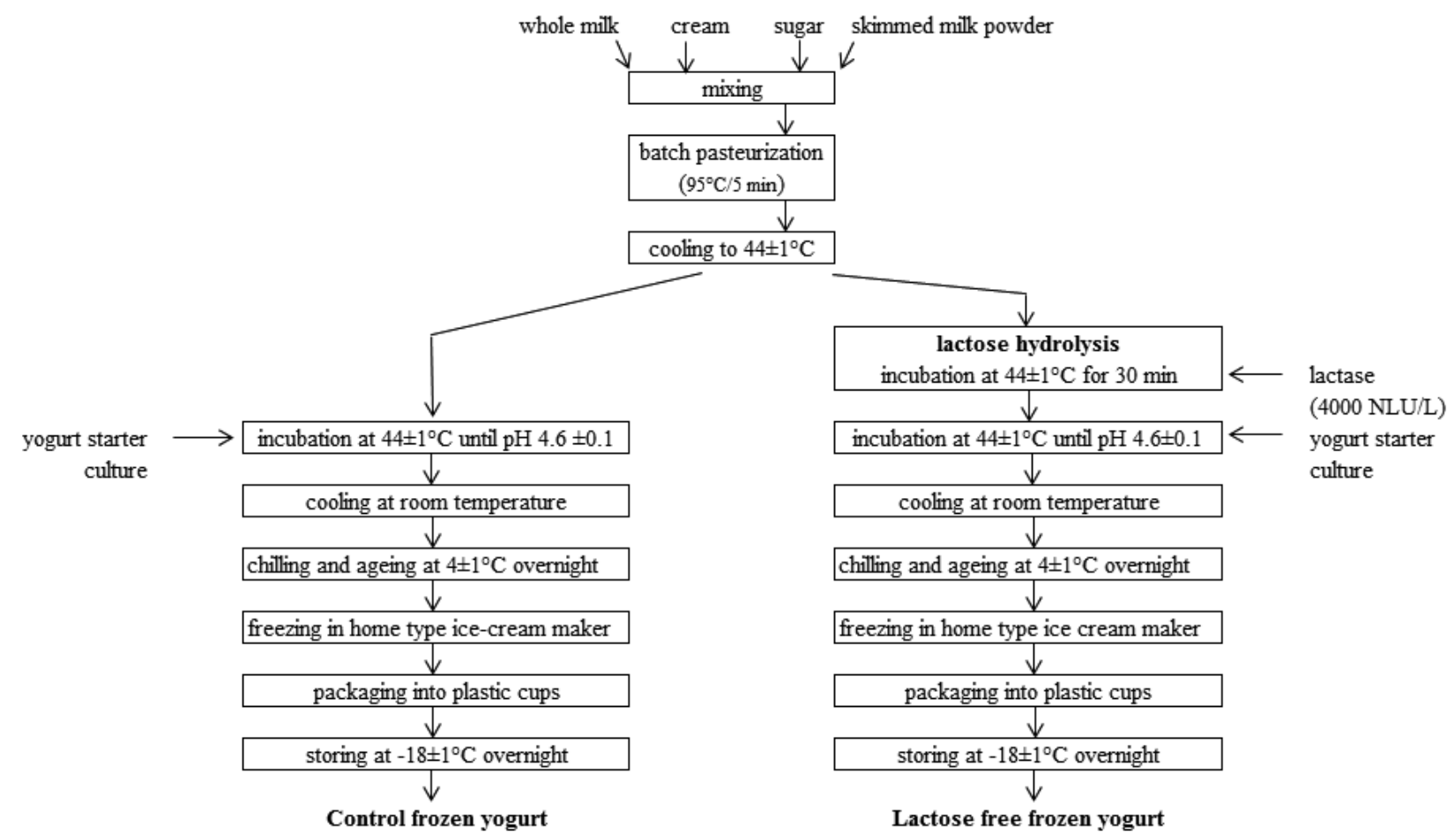

Fig. 1. Frozen yogurt production flow chart: NLU/L - Natural Lactase Units per litre

manufacturer's guidelines. $4000 \mathrm{NLU} / \mathrm{L}$ of commercial Ha-lactase ${ }^{\circledR}$ was added to the mixture 30 min prior to the starter culture to ensure there was sufficient time for lactose hydrolysis, which is performed simultaneously with fermentation until the $\mathrm{pH}$ is reduced to the value of 5.5, at which the enzyme is inactivated. Due to the fact that during the incubation of yogurt, the $\mathrm{pH}$ decreased to 5.5 after approx. $2.5 \mathrm{~h}$, the time of Ha-lactase activity amounted about $3 \mathrm{~h}$. According to the enzyme manufacturer, $2.5 \mathrm{~h}$ is sufficient time to reduce lactose content by almost $100 \% .0 .006 \mathrm{~g} / \mathrm{L}$ of the freeze-dried yogurt starter culture was added. The yogurt fermentation was conducted until the $\mathrm{pH}$ dropped to $4.6 \pm 1$. The yogurts were cooled at room temperature for about $3 \mathrm{~h}$ and aged under refrigeration $\left(4 \pm 1^{\circ} \mathrm{C}\right)$ overnight. The lactose-free and control yogurts were frozen in a home-type ice cream maker (Klarstein, Germany). Approximately $1000 \mathrm{~mL}$ of yogurt was converted to frozen yogurt and the production time was $40 \mathrm{~min}$. The frozen yoghurt was then filled into plastic containers and stored at $-18 \pm 1^{\circ} \mathrm{C}$ overnight (app. $16 \mathrm{~h}$ ).

\begin{abstract}
Methods
Physicochemical analyses. The chemical composition of yogurts was evaluated in accordance with Official Analytical Methods (AOAC, 1997) and Portuguese Standards Methods (IPQ, 1990). The protein content was estimated by the Kjeldahl method and the fat content using the Gerber method. Total solid content was determined by drying the samples at $105^{\circ} \mathrm{C}$. Ash content was assessed by incinerating dry samples in an electric muffle furnace (model LE 4/11/R6, Nabertherm, Germany). Moreover, $\mathrm{pH}$ and titratable acidity were measured in samples of yogurt and frozen yogurt. The $\mathrm{pH}$ was evaluated directly with a $\mathrm{pH}$-meter (model HI9025, HANNA Instruments, Italy). Titratable acidity, expressed as a percentage of lactic acid, was determined after titration using a $0.1 \mathrm{M} \mathrm{NaOH}$ solution (IPQ, 1990). In the case of frozen yogurts, the $\mathrm{pH}$ and titratable acidity were measured in melted samples.
\end{abstract}

Texture and viscosity of frozen yogurt. Yogurts and frozen yogurts were subjected to the assessment 
Skryplonek, K., Gomes, D., Viegas, J., Pereira, C., Henriques, M. (2017). Lactose-free frozen yogurt: production and characteristics. Acta Sci. Pol. Technol. Aliment., 16(2), 171-179. http://dx.doi.org/10.17306/J.AFS.2017.0478

Table 1. 5-point scale guidelines for frozen yogurt sensory evaluation

\begin{tabular}{lcll}
\hline Quality attributes & Weights for $O S Q$ calculation & \multicolumn{1}{c}{ Quality requirements } & \multicolumn{1}{c}{ Evaluated properties } \\
\hline Consistency & 0.45 & $\begin{array}{l}\text { smooth, homogenous, without ice } \\
\text { or lactose crystals } \\
\text { typical for frozen yogurt }\end{array}$ & $\begin{array}{l}\text { smoothness, sandiness, gumminess, } \\
\text { ice crystals occurrence }\end{array}$ \\
Taste and flavour & 0.35 & $\begin{array}{l}\text { lack of deformation, uniform, } \\
\text { creamy colour }\end{array}$ & colour, discoloration, deformations \\
Appearance & 0.20 & & \\
\hline
\end{tabular}

of their textural properties and viscosity. Before both analyses, yogurt samples were stored at $4 \pm 1{ }^{\circ} \mathrm{C}$ and frozen yogurt samples were tempered in refrigeration conditions $\left(4 \pm 1^{\circ} \mathrm{C}\right)$ for $4 \mathrm{~h}$ before the test. The texture analysis was performed by a cycle test with the use of a texture analyzer (model TA.XT Express Enhanced, StableMicro Systems, UK) and included the measurement of hardness (the peak force during penetration of the sample) and stickiness (the negative peak force during the withdrawal of the probe). The analysis was run with a penetration distance of $25 \mathrm{~mm}$ at $1 \mathrm{~mm} / \mathrm{s}$ test speed using a cylindrical $6 \mathrm{~mm}$ diameter acrylic probe. The viscosity of the samples was measured by a rotational viscometer (Brookfield Viscometer model DV II, Brookfield Engineering Inc., USA) at $20 \mathrm{rpm}$ with spindle number 5 . The volume of the sample was $150 \mathrm{~mL}$ and the immersion depth of the spindle was constant throughout the test. The assessments were carried out in ambient conditions, which simulated the conditions during ice cream consumption.

Overrun. Overrun of the frozen yogurts was measured as a comparison of the weight of the yoghurt and frozen yogurt with an equal volume of each. For calculation, the following formula was used (Akin et al., 2007):

Overrun $[\%]=\frac{\text { weight of yogurt }- \text { weight of frozen yogurt }}{\text { weight of frozen yogurt }} \cdot 100$

Colour measurement. The colour coordinates $\mathrm{L}^{*}, \mathrm{a}^{*}$ and $b^{*}$ of the frozen yogurts were determined on the product surface with a Minolta Chroma Meter colorimeter (model CR-200B, Konica Minolta, Japan), using the $L^{*} a * b *$ CIELAB system, previously calibrated with the white standard plate.
Sensory evaluation. The methodology followed for sensory analysis of frozen yogurts was based on the work of Akin et al. (2007). Evaluation included an assessment of consistency, taste and flavour and appearance (Table 1). The test was performed in laboratory conditions by a 6-person sensory trained panel specialising in dairy products. The samples were assessed according to a 5-point scale, where each quality attribute obtained a score from 1 (very poor quality) to 5 (no criticism). On the basis of the results, the overall sensory quality $(O S Q)$ was calculated, as a weighted mean of quality attribute scores (Table 1). The weights indicate the influence of each attribute on the product's attractiveness (Palka and Palich, 2008).

Statistical analysis. The experiment was performed in one repetition, all of the analyses were performed in triplicate and Student's t-test was used to evaluate the differences between samples' means. The level of significance was $(p<0.05)$. Statistical analysis was carried out using Microsoft Excel 2003 software (Microsoft Corporation, USA).

\section{RESULTS AND DISCUSSION}

The effect of lactose hydrolysis on the characteristics of the yogurts during yogurt production and of the final products was investigated. The chemical composition of yogurts is presented in Table 2. The results show that lactose hydrolysis did not influence fat, protein and ash content, although lactose-free yogurt was characterized by a slightly higher total solids content.

Table 3 presents $\mathrm{pH}$ and titratable acidity of yogurts and frozen yogurts. In the case of the yogurts' acidity, the influence of lactose hydrolysis was more 
Skryplonek, K., Gomes, D., Viegas, J., Pereira, C., Henriques, M. (2017). Lactose-free frozen yogurt: production and characteristics. Acta Sci. Pol. Technol. Aliment., 16(2), 171-179. http://dx.doi.org/10.17306/J.AFS.2017.0478

Table 2. Overall chemical composition of yogurts

\begin{tabular}{lcccc}
\hline \multicolumn{1}{c}{ Yogurt type } & Total solids, $\%$ & Fat, $\%$ & Protein, $\%$ & Ash, \% \\
\hline Control & $18.76 \pm 0.10^{\mathrm{A}}$ & $4.8 \pm 0.1^{\mathrm{A}}$ & $3.11 \pm 0.03^{\mathrm{A}}$ & $0.802 \pm 0.004^{\mathrm{A}}$ \\
Lactose-free & $19.46 \pm 0.07^{\mathrm{B}}$ & $4.8 \pm 0.1^{\mathrm{A}}$ & $3.15 \pm 0.02^{\mathrm{A}}$ & $0.805 \pm 0.005^{\mathrm{A}}$ \\
Student's t-test $p$-value & 0.0007 & 1.0000 & 0.2754 & 0.4555 \\
\hline
\end{tabular}

Different capital letters in superscript indicate statistically significant differences $(p<0.05)$.

Table 3. The $\mathrm{pH}$ and titratable acidity of yogurts and frozen yogurts

\begin{tabular}{llcc}
\hline & Product & $\mathrm{pH}$ & $\begin{array}{c}\text { Titratable acidity } \\
\% \text { lactic acid }\end{array}$ \\
\hline Yogurts & control & $4.44 \pm 0.01^{\mathrm{A}}$ & $0.914 \pm 0.004^{\mathrm{A}}$ \\
& lactose-free & $4.39 \pm 0.01^{\mathrm{B}}$ & $0.927 \pm 0.004^{\mathrm{B}}$ \\
& Student's t-test $p$-value & 0.0004 & 0.0158 \\
Frozen yogurts & control & $4.42 \pm 0.01^{\mathrm{A}}$ & $0.868 \pm 0.008^{\mathrm{A}}$ \\
& lactose-free & $4.43 \pm 0.01^{\mathrm{A}}$ & $0.887 \pm 0.007^{\mathrm{B}}$ \\
& Student's t-test $p$-value & 0.6779 & 0.0334 \\
\hline
\end{tabular}

Different capital letters in superscript indicate statistically significant differences $(p<0.05)$.

pronounced and the lactose-free variant had significantly higher acidity measured both by the $\mathrm{pH}$ method and by titration. These results indicate that breaking down lactose to monosaccharides facilitates bacterial metabolism and enhances the fermentation process. Frozen yogurts had lower titratable acidity than yogurts before freezing. Control and lactose-free frozen yogurts differed only in titratable acidity expressed as a percentage of lactic acid, and contrary to the unfrozen yogurts, the $\mathrm{pH}$ of frozen products did not differ.

The results of textural analysis and viscosity measurement, as well as the values of frozen yogurts overrun are showed in Table 4. The analyses of yogurt texture and viscosity did not reveal significant differences. Therefore we can conclude that replacing lactose with glucose and galactose has no effect on the viscosity and textural parameters of yogurt. Lactose hydrolysis had a significant influence on the texture and viscosity of frozen yogurts. The control product had higher hardness and stickiness, whilst lactose-free frozen yogurt had considerably higher levels of viscosity than control.
Low values of stickiness of both lactose-free and control products are consistent with the results of El-Nagar et al. (2002), who reported that low-fat frozen yogurt ( $5 \%$ fat) is considerably less adhesive than high-fat equivalents. The viscosity is a crucial indicator of ice cream and frozen yogurt quality, because it is directly related to the sensorial perception of the product. The greater the viscosity, the better the consistency and mouthfeel of the frozen dessert. Moreover, it has been stated (El-Nagar et al., 2002) that the viscosity of ice cream and frozen yogurt is connected with their meltdown characteristics. Higher viscosity is related to higher melting resistance due to the more stable fat-liquid emulsion of the product. Overrun is one of the most important properties of ice cream and other frozen desserts and it affects its texture and sensorial perception, as well as production profitability (Marshall et al., 2003). The results indicate that lactose hydrolysis has no influence on overrun capacity and the value of this parameter was approx. $32.5 \%$ for both products analyzed. Guner et al. (2007) reported that frozen dessert containing yogurt instead of milk 
Skryplonek, K., Gomes, D., Viegas, J., Pereira, C., Henriques, M. (2017). Lactose-free frozen yogurt: production and characteristics. Acta Sci. Pol. Technol. Aliment., 16(2), 171-179. http://dx.doi.org/10.17306/J.AFS.2017.0478

Table 4. Texture and viscosity of yogurts and frozen yogurts

\begin{tabular}{lcccc}
\hline \multicolumn{1}{c}{ Product } & Hardness, N & Stickiness, N & Viscosity, MPa·S & Overrun, \% \\
\hline Yogurts & & & & \\
$\quad$ control & $0.0210 \pm 0.0006^{\mathrm{A}}$ & $0.0057 \pm 0.0004^{\mathrm{A}}$ & $3000 \pm 100^{\mathrm{A}}$ & - \\
lactose-free & $0.0206 \pm 0.0006^{\mathrm{A}}$ & $0.0049 \pm 0.0005^{\mathrm{A}}$ & $2967 \pm 153^{\mathrm{A}}$ & - \\
$\quad$ Student's t-test $p$-value & 0.5185 & 0.0936 & 0.7676 & - \\
Frozen yogurts & & & & \\
control & $0.3051 \pm 0.0155^{\mathrm{A}}$ & $0.0969 \pm 0.0080^{\mathrm{A}}$ & $1910 \pm 110^{\mathrm{A}}$ & $32.7 \pm 1.1^{\mathrm{A}}$ \\
lactose-free & $0.1880 \pm 0.0148^{\mathrm{B}}$ & $0.0668 \pm 0.0022^{\mathrm{B}}$ & $3467 \pm 115^{\mathrm{B}}$ & $32.3 \pm 1.4^{\mathrm{A}}$ \\
Student's t-test $p$-value & 0.0007 & 0.0033 & 0.0001 & 0.7626 \\
\hline
\end{tabular}

Different capital letters in superscript indicate statistically significant differences $(p<0.05)$.

has lower viscosity and lower overrun in comparison with traditional ice cream. During the production of frozen yogurt with $10 \%$ fat, $18 \%$ sucrose, $12 \%$ MSNF and salep as a stabilizer, they obtained lower overrun values ranging between $25 \%$ and $29 \%$. In contrast, Moeenfard and Tehrani (2008) did not determine poor overrun capacity of frozen yogurt. For frozen yogurt with $10 \%$ fat, $13 \%$ MSNF, $13 \mathrm{~g} / 100 \mathrm{~g}$ of sucrose and three kinds of stabilizers, the overrun amounted to 40 $45 \%$. The authors connected high overrun values with the presence of stabilizers, which prevent air bubbles from collapsing. In the work of Güven and Karaca (2002), overrun of vanilla frozen yogurt with different sugar content ranged from 22 to $32 \%$ and was positively influenced by the level of sucrose. Moreover, increasing the sugar content softened the structure and increased the viscosity of frozen yogurt. In a study on probiotic ice cream, Akin et al. (2007) also reported the positive influence of sugar content on overrun and viscosity. The overrun values of probiotic ice cream ranged from 34 to $37.5 \%$. Lactose hydrolysis leads to an increase in the osmotic concentration of the sugars, because glucose and galactose have half the molecular weight of lactose. Consequently, monosaccharides depress the freezing point of the mix more than lactose or sucrose (Whelan et al., 2008). Thus the effect of lactose breaking down on textural and viscosity should more pronounced than the effect of adding sugar. Our results confirmed this assumption and a decrease in the hardness and an increase in the viscosity in lactose-free samples were observed. However, no influence on overrun capacity was noticed.

Colour is an important factor of frozen yogurt's attractiveness. It should represent the colour of yogurt and be homogenous. The colour of frozen yogurts was uniform and creamy. Measurements made with a colorimeter showed that lactose-free frozen yogurt had a significantly higher value of $\mathrm{L}^{*}$ parameter, which means that it was brighter than the control product. The negative values of the $\mathrm{a}^{*}$ parameter and positive values of the $b^{*}$ parameter indicpoint to the green-yellow colour characteristics of the samples (Fig. 2).

The results allow us to state that physicochemical changes caused by lactose hydrolysis in the yogurt affect the lightness index L*. The difference in $\mathrm{L}^{*}$ value cannot be explained by differences in the titratable acidity of the products, because, according to Cais-Sokolińska and Pikul (2006), higher acidity causes a decrease in the lightness index $\mathrm{L}^{*}$ value in yogurt. This observation is contrary to our results, where lactose-free yogurt was more acid. A lighter colour of lactose-free samples was positively assessed by the panellists during sensory evaluation of products.

Sensory characteristics like mouthfeel, creaminess, perception of ice crystals and consistency are crucial factors in consumers' product acceptance (Stampanoni et al., 1996). The levels of sensory characteristics and overall sensory quality of frozen yogurts are shown in Figure 3. The panellists graded lactose-free frozen 


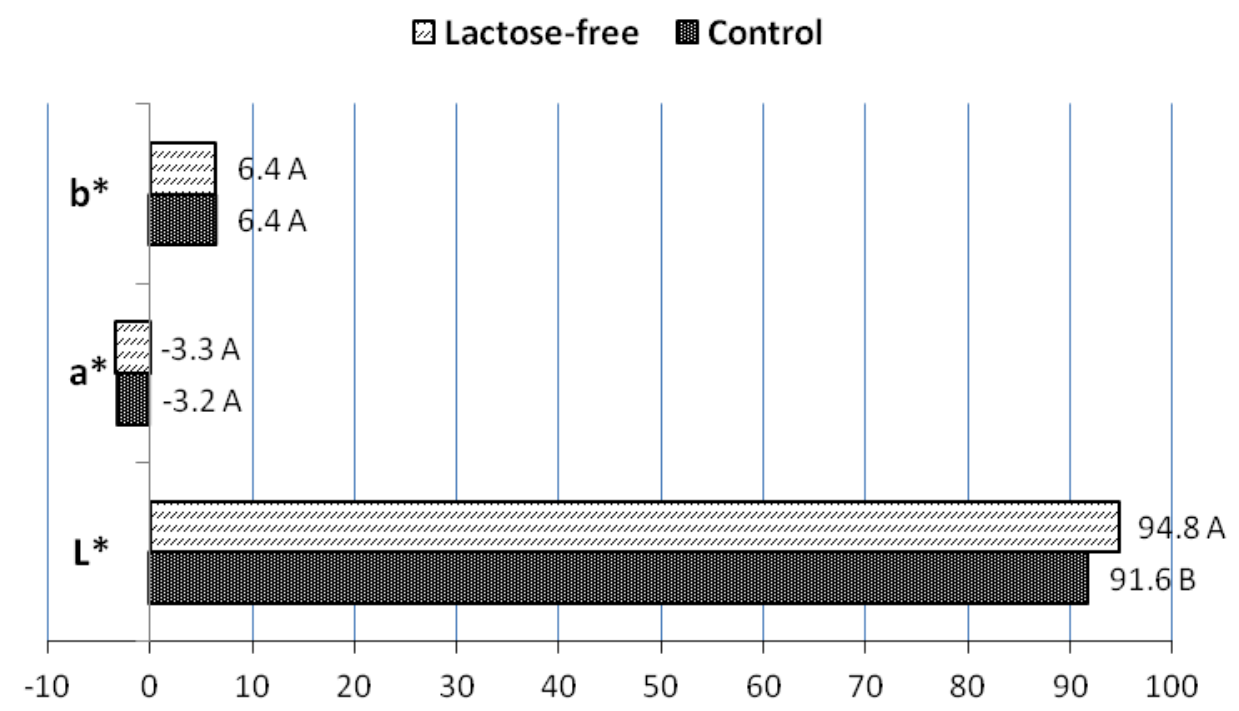

Fig. 2. Colour parameters $\left(\mathrm{L}^{*}, \mathrm{a}^{*}, \mathrm{~b}^{*}\right)$ of frozen yogurts. Different capital letters indicate statistically significant differences $(p<0.05)$

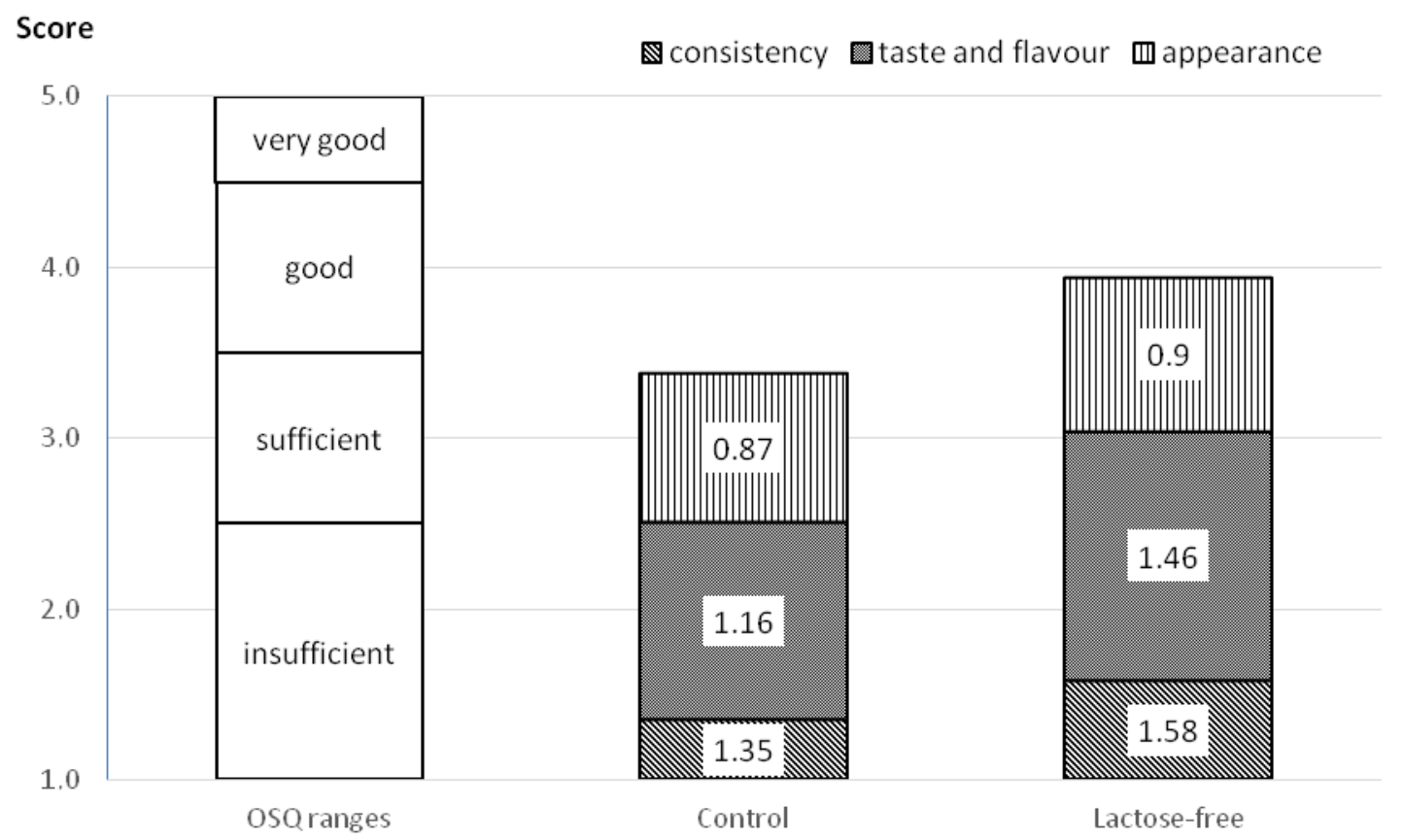

Fig. 3. Sensory evaluation of frozen yogurts

yogurt higher than the control product. This product had better consistency, as well as taste and flavour sensations, whilst the appearance of both products was similar. Overall, the sensory quality of lactose-free desserts was estimated as good, whilst the control product obtained a sufficient rating.

The control frozen yogurt was gritty and not creamy enough. Its icy, coarse structure was caused 
by the presence of large ice crystals detectable in the mouth. The lactose-free variant did not have such symptomatic defects and was described as creamy and smooth and had a more distinct sweet taste than the control (Fig. 3). Moreover, in these products ice recrystallization occurred, although ice crystals were much smaller and the consistency was just slightly gritty. The icy texture of the samples was possibly the outcome of a low fat content and lack of stabilizers in the formulation. In the work of El-Nagar et al. (2002) low-fat frozen yogurt (5\% fat, $14 \mathrm{~g} / 100 \mathrm{~g}$ sugar) had poor sensory characteristics due to the hard, icy, coarse and gritty consistency. The authors indicated low fat content as being a reason for these drawbacks. Fat content affects the sensory properties of frozen desserts. A reduction in fat causes less creamy and poorer mouth-coating characterisitics and enhances the perception of ice crystals in ice cream (Guinard et al., 1997; Stampanoni et al., 1996). Besides contributing to flavour, sweeteners also have an influence on mouthfeel and consistency and together with stabilizers are the most important determinants of ice recrystallization. An increase in sugar concentration reduces crystal perception and enhances the creamy and mouthcoating sensation. These properties depend on the type and concentration of sweeteners and are primarily connected with the freezing point of the ice cream mix. Ice creams with a lower freezing point contain smaller ice crystals (Hagiwara and Hartel, 1996; Trgo et al., 1999). Our results were consistent with this statement and lactose-free frozen yogurt containing glucose and galactose had distinctly less perceptible ice crystals and better consistency. The occurrence of ice crystals perceived especially in the control product may be overcome by adding hydrocolloid stabilizers, which retard ice recrystallization and have a positive impact on viscosity (Isik et al., 2011). The results revealed that lactose hydrolysis can significantly improve the sensorial characteristics of frozen yogurt.

\section{CONCLUSIONS}

The study showed that lactose-free frozen yogurt may be used successfully for frozen yogurt production. Lactose hydrolysis allows the manufacture of a new kind of frozen yogurt which is suitable for consumers with lactose intolerance. An important factor is the enhancement of the sweetness of the product without increasing the calorie content. Moreover, by breaking down lactose into monosaccharides, the freezing point of yogurt is reduced, which consequently greatly improves the texture and viscosity of the product, prevents ice recrystallization and may curb the melting rate even without the addition of stabilizers. Lactose hydrolysis resulted in a lighter colour of the product and improved its sensory quality. The results of this study may be useful for ice cream and frozen yogurt manufacturers to produce novel lactose-free frozen desserts.

\section{REFERENCES}

Akin, M. B., Akin, M. S., Kirmaci, Z. (2007). Effects of inulin and sugar levels on the viability of yogurt and probiotic bacteria and the physical and sensory characteristics in probiotic ice-cream. Food Chem., 104, 93-99. http:// dx.doi.org/10.1016/j.foodchem.2006.11.030

AOAC. (1997). Official methods of analysis of Association of Official Analytical Chemists. 16th ed. Vol. 2. 33 Dairy Products USA.

Brown-Esters, O., Mc Namara, P., Savaiano, D. (2012). Dietary and biological factors influencing lactose intolerance. Int. Dairy J., 22, 98-103. http://dx.doi. org/10.1016/j.idairyj.2011.09.010

Cais-Sokolińska, D., Pikul, J. (2006). Use of colour measurement to evaluate yoghurt quality during storage. Ital. J. Food Sci., 18, 1, 63-71.

Devereux, H. M., Jones, G. P., McCormack, L., Hunter, W. C. (2003). Consumer acceptability of low fat foods containing inulin and oligofructose. J. Food Sci., 68, 5, 1850-1854.

El-Nagar, G., Clowes, G., Tudorică, C. M., Kuri, V., Brennan, C. S. (2002). Rheological quality and stability of yog-ice cream with added inulin. Int. J. Dairy Technol., 55, 2, 89-93.

Gänzle, M. G., Haase, G., Jelen, P. (2008). Lactose: Crystallization, hydrolysis and value-added derivatives. Int. Dairy J., 18, 685-694. http://dx.doi.org/10.1016/j. idairyj.2008.03.003

Goff, H. D., Hartel, R. W. (2004). Ice cream and frozen desserts. In Y. A. Hui (Ed.), Handbook of frozen products. CRC Press.

Guinard, J. X., Zoumas-Morse, C., Mori, L., Uatoni, B., Panyam, D., Kilara, A. (1997). Sugar and fat effects 
Skryplonek, K., Gomes, D., Viegas, J., Pereira, C., Henriques, M. (2017). Lactose-free frozen yogurt: production and characteristics. Acta Sci. Pol. Technol. Aliment., 16(2), 171-179. http://dx.doi.org/10.17306/J.AFS.2017.0478

on sensory properties of ice cream. J. Food Sci., 62, 5, 1087-1094.

Guner, A., Ardic, M., Keles, A., Dogruer, Y. (2007). Production of yogurt ice cream at different acidity. Int. J. Food Sci. Tech., 42, 948-952. http://dx.doi.org/10.1111/ j.1365-2621.2006.01315.x

Güven, M., Karaca, B. (2002). The effects of varying sugar content and fruit concentration on the physical properties of vanilla and fruit ice-cream-type frozen yogurts. Int. J. Dairy Technol., 55, 1, 27-31.

Hagiwara, T., Hartel, R. W. (1996). Effect of sweetener, stabilizer, and storage temperature on ice recrystallization in ice cream. J. Dairy Sci., 79, 735-744.

Isik, U., Boyacioglu, D., Capanoglu, E., Nilufer Erdil, D. (2011). Frozen yogurt with added inulin and isomalt. J. Dairy Sci., 94, 1647-1656. http://dx.doi.org/10.3168/ jds.2010-3280

Lopez, M. C., Medina, L. M., Jordano, R. (1998). Survival of lactic acid bacteria in commercial frozen yogurt. J. Food Sci., 63, 4, 706-708.

Marshall, R. T. (2003). Ice cream and frozen desserts. In H. Roginski, J. W. Fuquay, P. F. Fox (Ed.), Encyclopaedia of dairy sciences (pp. 1367-1375). London: Academic Press.

Messia, M. C., Candigliota, T., Marconi, E. (2007). Assessment of quality and technological characterization of lactose-hydrolyzed milk. Food Chem., 104, 910-917. http://dx.doi.org/10.1016/j.foodchem.2006.12.045
Milani, E., Koocheki, A. (2011). The effects of date syrup and guar gum on physical, rheological and sensory properties of low fat frozen yoghurt dessert. Int. J. Dairy Technol., 64, 1, 121-129. http://dx.doi.org/10.1111/ j.1471-0307.2010.00631.x

IPQ - Portuguese Institute of Quality. (1990). Milk and dairy products. Portuguese standards. Lisboa, Portugal [in Portuguese].

Moeenfard, M., Tehrani, M. M. (2008). Effect of some stabilizers on the physicochemical and sensory properties of ice cream type frozen yogurt. Am.-Eurasian J. Agric. Environ. Sci., 4, 5, 584-589.

Palka, A., Palich, P. (2008). Influence of temperature fluctuation on some quality properties of ice cream. Acta Agrophysica, 12, 3, 755-765 [in Polish].

Stampanoni Koeferli, C. R., Piccinali, P., Sigrist, S. (1996). The influence of fat, sugar and non-fat milk solids on selected taste, flavor and textural parameters of a vanilla ice-cream. Food Qual. Prefer., 7, 2, 69-79.

Trgo, C., Koxholt, M., Kessler, H. G. (1999). Effect of freezing point and texture regulating parameters on the initial ice crystal growth in ice cream. J. Dairy Sci., 82, 460-465.

Whelan, A. P., Vega, C., Kerry, J. P., Goff, H. D. (2008). Physicochemical and sensory optimisation of a low glycemic index ice cream formulation. Int. J. Food Sci. Techn., 43, 1520-1527. http://dx.doi.org/10.1111/j.1365-2621. 2007.01502.x 